\title{
The Fuzzy Boundaries in Start-up Firms Industries. A Social Network Analysis
}

\author{
Jubalt Alvarez-Salazar ${ }^{1}$
}

\begin{abstract}
This paper aims to explore and describe the way in which startup firms are grouped into industries. To this end, a quantitative research approach is presented, applying a social network analysis to a sample of Pacific Alliance startups, which were recorded in CrunchBase, considering their operational activities as linkage criteria. In this way, this document offers a new application to social network analysis to demonstrate the need for a different way of classifying startups that goes beyond the industry boundaries established by the traditional classification systems. It also shows that Pacific Alliance startup industries are structured according to a pattern of dominant activity, applied technology and specific use. In addition, there is a concentration on mature or declining startup industries, while growing industries are left in second order.
\end{abstract}

Keywords: Industry boundaries, Startups, Social Network Analysis, Pacific Alliance.

Submitted: May $26^{\text {th }}, 2020 /$ Approved: November $25^{\text {th }}, 2020$

\section{Introduction}

The Pacific Alliance was created by Chile, Colombia, Mexico and Peru as a mechanism for political, economic, cooperation and integration articulation with the aim of promoting growth and competitiveness in their economies (Alianza del Pacífico, 2016). These countries not only have in common that they have been the fastest growing economies in Latin America, they also have linguistic, cultural and political similarities that could facilitate a joint development ( $\mathrm{PwC}, 2016)$. But they also must face the same shortcomings for their startups to be successful. According to the Dynamic Entrepreneurship Index (Kantis, Federico, \& Ibarra, 2019), they have in common a weakened STI platform, underdeveloped human resources that avoid the development of high-tech ventures, scarce financing for highly uncertain initiatives, and weak and unskilled social capital.

The promotion of innovative entrepreneurship is a positive driver of economic growth (Acs, 2010). The Pacific Alliance countries with different levels of intensity and implementation mechanisms promote initiatives to foster the development of these ventures; and although there are no theoretical references on the integration of entrepreneurial ecosystems, there may be integration spaces that generate opportunities of scale and heterogeneity for the startups of the alliance (Kantis, Federico, \& Magendzo, 2016). However, to identify in a specific way the opportunities and challenges of these ventures requires a clear definition of the boundaries of the industry in which they compete (Porter, 2009). This will allow for consistent and comparable information for decision making (Phillips \& Ormsby, 2016).

For example, the three main obstacles to entrepreneurship development in the four Pacific Alliance countries are funding, networking and lack of preparation (Álvarez et al., 2018). his conclusion could lead to wrong decisions by public policy makers if a distinction is made in the first place between traditional entrepreneurship and startups (Aulet, 2013). Although in both cases, the initial financing is provided by the entrepreneur, as growth is generated, the traditional venture may turn to the financial system, while the startup will require private capital investors (Wright, 2017)entrepreneurs may be misled on the role and relative size of this financing model. In reality however, $\mathrm{VC} / \mathrm{PE}$ is quite difficult to obtain, particularly for young entrepreneurs. With this in mind, I assess seven popular models for financing that may be of interest to entrepreneurial students. These seven models include: self-funding/bootstrapping; friends, family, and colleagues; banks; accelerators; angel investors; peer-topeer (P2P. But being a startup, accessing private capital has different processes for a fully digital startup than one that uses knowledge intensively with AgTech or BioTech, while the former can easily access a network of angel investors, the latter will require the support of an incubator to access specialized investors (Alvarez Salazar, 2020). Thus, public policies aimed at financing innovative entrepreneurship should first identify the singularities of the group of startups to be promoted. This implies having a classification of specific industries. This applies to the other two obstacles related to policies to promote social capital and human capital in startups.

But this is also important for startup founders making decisions. For example, a startup that aims to promote tourism as an opportunity for community empowerment, using artificial intelligence to identify preference patterns in potential customers, not only competes with Travel Tech, but also with social media startups, and possibly with AI startups if their algorithms are flexible enough to have other applications. Then, defining your strategies will require understanding how startups with a similar profile cope with the environment with their organizational resources (Isenberg \& Dillon, 2013).

Nevertheless, identifying the boundaries of the startup industries could be a complicated process. Since startups have the capacity to generate important changes in social and economic activities (OCDE, 2016). Applying the traditional industrial classification to these ventures is not representative of the activities they develop (Libert, Beck, \& Wind, 2016). This is best illustrated in Table 1, which shows the classification in official records for four startups, which are leaders in

1) Pontificia Universidad Católica del Perú. E-mail: jubalt.alvarez@pucp.edu.pe 
terms of their innovative capacity, in the different countries of the $\mathrm{Pa}$ cific Alliance. From this table it can be seen that the categories assigned by the official rating systems have little relation to the categories assigned by CrunchBase, one of the main digital platforms specialized in managing firm information to facilitate investment decisions by private investors and venture capitalists (Ingham \& Kodner, 2017).

Table 1. Comparison between categories of economic activities of startups

\begin{tabular}{|c|c|c|c|c|c|}
\hline \multirow{2}{*}{ Startup } & \multicolumn{4}{|c|}{ International Standard Industrial Classification } & \multirow{2}{*}{ CrunchBase Category } \\
\hline & Country & Type & Code & Category & \\
\hline Crehana & Peru & CIIU & 8549 & Other Types of Education N.C.P.* & $\begin{array}{l}\text { Collaborative Consumption } \\
\text { E-Learning } \\
\text { EdTech } \\
\text { Internet }\end{array}$ \\
\hline Snuuper & Chile & CIIU & 8299 & $\begin{array}{l}\text { Other Business Support Services Activi- } \\
\text { ties N.C.P.* }\end{array}$ & $\begin{array}{l}\text { Consumer } \\
\text { Crowdsourcing } \\
\text { Information Technology } \\
\text { Market Research } \\
\text { SaaS } \\
\text { Sharing Economy }\end{array}$ \\
\hline Rappi & Colombia & CIIU & 6209 & $\begin{array}{l}\text { Other Information Technology and Com- } \\
\text { puter Services Activities }\end{array}$ & $\begin{array}{l}\text { Food Delivery } \\
\text { Grocery } \\
\text { Marketplace } \\
\text { Restaurant }\end{array}$ \\
\hline Sr. Pago & Mexico & SCIAN & 561440 & Payment Collection Agencies & $\begin{array}{l}\text { E-commerce } \\
\text { E-commerce Platforms } \\
\text { Fintech } \\
\text { Mobile } \\
\text { Mobile Payments }\end{array}$ \\
\hline
\end{tabular}

Note: (1) Prepared from public information on tax agency websites, in the case of Peru (SUNAT), Chile (SII) and Colombia (DIAN). (2) In the case of Mexico, information published in the Directory of Empresarial Mexicoo.mx. (3) The CruchBase categories were obtained for each startup from https://www.crunchbase. com/search-home. (4) Searches were performed on 06/18/2018. ${ }^{*}$ Not Previously Classified.

So, if industrial classification systems no longer represent startup industries, how come startups are grouped into industries? To answer this, a social network analysis was applied considering the linkage created between startups by the categories registered for these ventures in the CrunchBase database for a sample of startups created in the Pacific Alliance countries that were successful in obtaining funding from private equity investors or venture capital funds. It follows that the objective of this research is to explore and describe how startup companies in Pacific Alliance countries that have achieved financing are grouped into industries based on their economic activities registered for those companies. As a result, we identified a pattern of organization of activities that are structured into industries, proposed a categorization for these industries, and revealed the concentration of startups in mature or declining industries, leaving aside growth industries.

\section{Conceptual Framework}

\section{The Industry's Definition}

Understanding how industries are configured is critical to information generation and decision making in business(Munir \& Phillips, 2002). For this reason, the concept of sector or industry has been studied in the field of management from different theoretical approaches, the most frequent being the perspective of the theory of resources and capabilities, and from the perspective of competitive advantage as a legacy of the theory of industrial organization (Yao, Si, \& Ye, 2016).

From the competitive advantage approach, an industry is formed when firms carry out economic activities, which are homogeneous in nature, to generate products that are similar to each other, so that they can be close substitutes for a common group of buyers (Bain, 1959; Porter, 1998). The Resource Based Theory adds that firms form industries by considering common competencies to generate differentiated products to compete in a specific market (Bettis, 1998). From this approach, information becomes an essential resource and information-based competition is what redefines industries (Sampler, 1998). This is a consequence of the fact that products stop being static and evolve in an accelerated way, making industries constantly transform (Tatsumoto, 2018). Considering the above, it could be argued that an industry would be better defined as a set of information assets that allow the generation of goods or services that are connected in networks of transactions, competition or complementation, through processes that are governed by companies to meet the needs or desires of their customers in the market (Fujimoto, 2018). 
Porter (2008) argues that industry boundaries are defined by two primary dimensions, product scope and geographic scope, but this may be partially applicable to startup industries. Information flows in a digital economy allow the knowledge generated to be disseminated more quickly and to be easily accessible to entrepreneurs, reducing trade restrictions and making human capabilities easily transferable between geographical areas (Hougaard \& Duus, 2017). In addition, highly specialized human capabilities, such as those required for the application of artificial intelligence, are cross-used between startups in different industries (Bessen, Impink, Seamans, \& Reichensperger, 2018). Furthermore, new technology companies, which create disruptions in industries, are born thinking about being global, changing the structure of industries in a given geographical area when they start operating there (Kuivalainen, Saarenketo, \& Puumalainen, 2012). These characteristics related to the creation and operation of startups mean that the boundaries between the industries in which these ventures are categorized become diffuse, making the definition of the industry in startups more complex than in traditional companies.

\section{The Diffuse Boundaries of Startup Industries}

The industrial classification systems frequently used are based on the theory of industrial organization (Munir \& Phillips, 2002). Their purpose is to generate a coherent standard that allows the collection, analysis and reporting of information useful for decision making by economic agents (United Nations, 2008). The International Standard Industrial Classification (ISIC) takes as discrimination criteria, the characteristics of the products that are generated, the uses given to them and the inputs, processes and production technology used (Phillips \& Ormsby, 2016). This system is used in most nations of the world, and there are even regional classifications derived from it, such as NACE for the European Union, SCIAN for North America and ANZSIC for Oceania (T. Y. Kim, Koo, Ook, \& Kim, 2014).

Then, in most nations of the world, firms are classified with a structure that corresponds to the context of the second and third industrial revolution. But, the innovative ventures that are created today, exploit the opportunities offered by the fourth industrial revolution, merging the physical, digital and biological domains (Schwab, 2016). This makes the boundaries between the industries are rapidly disintegrating as technological developments complement each other for use in applications that go beyond their original designs (Libert et al., 2016). Because of their innovative nature, the emergence of startups is generating transformations in all industries through the creation of continuously evolving digital platforms to meet the desires and needs of consumers as never before (Parker, Van Alstyne, \& Choudary, 2016).

This transformation has taken place in short periods of time. According to Steve Case (2016), between 1985 and 1999, pioneering companies built the infrastructure and the foundations for the development of online businesses; developing hardware, software and networks that interconnected people, companies and other organizations. Case adds that, between 2000 and 2015, large companies were generated that exploited the information generated by an interconnected world, creating infinitely scalable and replicable business models, taking advantage of the development of apps, smartphones and a digital connectivity that turned out to be ubiquitous. In his analysis, this author considers that currently the emerging companies use this digital connectivity, but are no longer completely defined by it; now it is a matter of integrating the digital to all social and economic activities, which will generate disruptions in all industries (Case, 2016).

\section{XTech Industries}

The result of the diffuse boundaries of the startup industries is that the traditional ISIC classification and its derivatives have lost their usefulness in providing comparable information for investment decisions among startups. Because of this, the main digital platforms specialized in generating information for private investors and venture capitalists, such as PrivCo, CB Insights, CrunchBase and PitchBook, have developed their own classification systems (Ingham \& Kodner, 2017; Lougen, 2017; Sharma, 2017). Defining the startup industries implies grouping these ventures by a higher level of specialization, this added to the development of new technologies, has led to the creation of new terms to call them, like FinTech, CleanTech or InfoTech (Rajahonka, 2019).

Indeed, the CrunchBase and PitchBook databases organize their classification by vertical industries (Crunchbase, 2019; Pitchbook, 2019). This could be an indication that startups are classified considering that their value propositions and the resources and capabilities needed to generate them are homogeneous among startups in the same industry (Mohr, Sengupta, \& Slater, 2010). The result of classifying the new companies by vertical industries is that it opens several possible categories. But only some XTech industries are attractive to founders and investors (Startup Genome, 2018). This also generates that XTech industries have accelerated life cycles. As happened with the EdTech in just one year it turned from a growing industry to a declining one (Startup Genome, 2018, 2019).

But just because a startup is categorized in a specific Xtech, it doesn't mean that it is the only vertical industry in which it operates. In fact, as shown in table 1, startups do it in different industries simultaneously. This can be explained by the Theory of Causation and Effectuation explained by Sarasvathy (2001). As ventures that seek to introduce innovations into the market, perform constant experiments, which implies making incursions with different types of technologies and resources, which previously were not necessarily used in the industries in which they operate. Of course, this is directly linked to the human and social capital of the founders, since as they participate in different networks that cross the boundaries of knowledge (Kodama, 2017), innovations are generated that are exploited by the startups.

The fact that startups operate in crossover Xtech industries is also a manifestation of the dynamic capabilities that characterize startups (Alvarez Salazar, 2020). In essence, the process of experimentation is an expression of the capabilities of sensing, learning, integrating and coordinating (Pavlou \& El Sawy, 2011; Teece, 2007). In very short periods of time, entrepreneurs identify opportunities, design a minimum viable product and test it in the target market, generating learning that is integrated into the process, which is then the basis for coordination of organizational resources. 
In this learning process, the participation of the client is a key aspect, since it implies working in crossed contexts, where the process of co-creation implies seeking solutions from diverse origins (Coviello \& Joseph, 2012). This is how startups create value by identifying any resource accessible to them that has the potential to contribute to the problem to be solved, a definition that is known as entrepreneurial bricolage (Baker \& Nelson, 2005). Finally, they adhere to a well-known mantra popularized by Levin, "fall in love with the problem not the solution" (as cited in Clark, 2014), which generates that startups eventually act in crossed vertical industries, so the borders between these become diffuse.Methodology

\section{Methodology}

\section{Research Design.}

Due to the nature of the data analyzed and the technique used in this research, this is a mixed scope study with an exploratory and descriptive approach. Teddlie \& Tashakkori (2009), remark that social network analysis (SNA), by including two types of data: matrices and network diagrams, is an "inherently mixed analysis technique" (p. 236). The treatment of quantitative data is an exploratory approach that requires the use of metrics that allow the comparison and evaluation of the elements in analysis (De Nooy, Mrvar, \& Batagelj, 2018). These metrics can be useful at the network level, focusing on assessing network cohesion and robustness, the presence of communities and the relationships between these (R. A. Hanneman \& Riddle, 2011b).

On the other hand, there are metrics at the nodal level, which allow understanding the way in which the agents participating in the network are integrated to it, focusing on assessing the connections that the agent has in the network, the power that the network provides to the agent for its capacity of intermediation and the centrality of the agent for the position it occupies in the network (R. A. Hanneman \& Riddle, 2011b).

Instead, the interpretation of the network diagram is a process that is tied to the subjectivity of the researcher, since the shape of the network, the size of the nodes and the colors selected are chosen through iterative procedures to identify patterns that emerge inductively and that support the researcher's statements regarding the phenomenon under study; thus, it is a qualitative approach that is executed simultaneously with the analysis of network and node metrics (Yousefi Nooraie, Sale, Marin, \& Ross, 2020). Thus, following Teddlie \& Tashakkori (2009), the integration of quantitative and qualitative data follows a comparative profile, given that the vertical industries with the highest level of centrality have been chosen and through comparisons the dominant industries have been identified, which has been the basis of the proposed classification, as will be seen below.

The analysis of social networks is based on the study of the links between people, organizations, places or situations that are involved by the activities they perform, allowing the identification of patterns, causes and effects of phenomena of interest to natural and social science research (Marin \& Wellman, 2011). In addition, the detection of communities is a common process in social network analysis (Fortunato, 2010). This aims to find sub-groupings within a network that have many links between the nodes of the network and few links with other sub-groupings (Missaoui \& Sarr, 2014). As previously mentioned, industries are configured by information networks that allow the generation of products that could be similar or complementary to the markets they are targeting (Fujimoto, 2018). Then, if the industries are networks of companies, an analysis of social networks oriented to the detection of communities will allow to identify the industries that are conformed in that network.

A social network is constituted by nodes (the agents that interrelate in the network) and edges (the links that are generated by the interrelation of the agents), the configuration of these components allows characterizing a network (Carrington \& Scott, 2011). In this way, the edges can define a direction to indicate the sense of the relationship (asymmetric networks), or it can be that, by the nature of the relationships, the edge does not require a sense (symmetric networks); in addition, networks can be constituted by links between the same type of agents, called one mode networks, or between different types of agents, called two mode networks (R. A. Hanneman \& Riddle, 2011a).

Considering the nature of the relationships between startups by the activities with which they are characterized in CrunchBase, the startup industries are one mode symmetrical networks. In this way, startup industries can be compared by the general structure of the network itself and by the behavior of its nodes. In addition, the linkages of nodes classified in different industries may suggest whether the boundaries between those industries are diffuse.

\section{Data Collection}

The analysis was carried out on a database of startups, registered in CrunchBase, which are primarily located in Pacific Alliance countries. Since social network analysis was used, it was necessary to define the boundaries of the study population (R. Hanneman \& Riddle, 2005). For this purpose, the selection criteria were to have received monetary resources from public funds, private investors, or venture capital funds. This is because when a startup manages to attract funding, it is more likely to survive (Hechavarría, Matthews, \& Reynolds, 2016). Therefore, it has an active commercial activity, and it is possible to define the industry in which it competes. Thus, the sample under analysis is composed of 775 startups (315 Chileans, 295 Mexicans, 115 Colombians and 50 Peruvians). In this one, the most frequent is that only one investor supports them $\left(\mathrm{x}^{-}=2.26 ; \sigma=3.45\right)$. However, $42 \%$ of these ventures have at least one lead investor. In addition, these startups most frequently register 3 items of economic activity in which they operate $\left(\mathrm{x}^{-}=3.27 ; \sigma=1.36\right)$.

\section{Data Analysis}

The node table was used to identify the startup communities in the study population from the linkages generated by the industry categories in which they compete. The node table was developed (each startup is a 
node in the analysis) and then the linkages between startups were determined, thus creating a 'one way' adjacency matrix. The procedure for constructing this matrix can be seen in the example shown in Figure 1, which shows that the more industries are shared between two startups, the linkage generated will have a greater weight, which is reflected in the adjacency matrix. In this way, the input was generated that allowed to identify how the startups are grouped to generate communities. In the example, at first sight it can be concluded that SUP3 and SUP4 formed a community. But when you have hundreds of related nodes this is a complicated task without a clustering algorithm.

Figure 1. Procedure for generating an adjacency matrix of links between startups by activities registered in CrunchBase

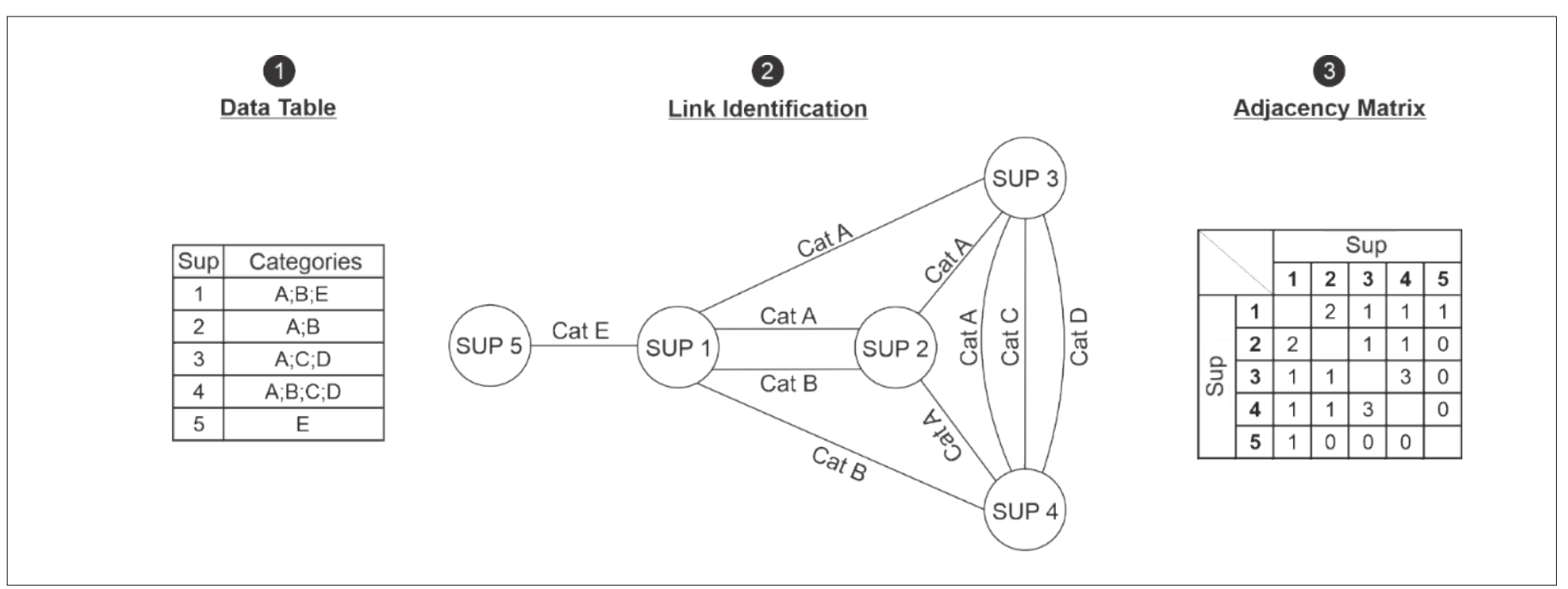

Subsequently, the communities were determined using Gephi 0.9.2. with the clustering algorithm of Blondel, Guillaume, \& Lefebvre (2008). Since this has the weakness of not detecting small communities (Fortunato, 2010), the resolution weighting was applied in the modularity function with a value of 0.4 generating more communities (Lambiotte, Delvenne, \& Barahona, 2014). Then, the industries that make up each community were identified. To do this, it was necessary to analyze the networks that are formed from this disaggregated information. However, the object of the analysis was no longer the startup but the registered industry. This required the elaboration of industry networks for each identified community. Thus, the nodes became the industries, and the links were generated by the startups that share the same industry. In this way, adjacency matrices were developed, in which the links have greater weight as a greater number of startups share the same industry. This can be seen graphically in Figure 2 .

In this way, the fictional community proposed as an example can be seen to be composed of eight categories of vertical industries. But it can be identified that category $\mathrm{A}$ is the dominant industry, because it has a greater number of linkages. Again, in an example with few nodes it is an easy task, but in the analyzed community networks it was necessary to use some metrics.

Figure 2. Procedure for the generation of adjacency matrix of activities registered in a specific community.

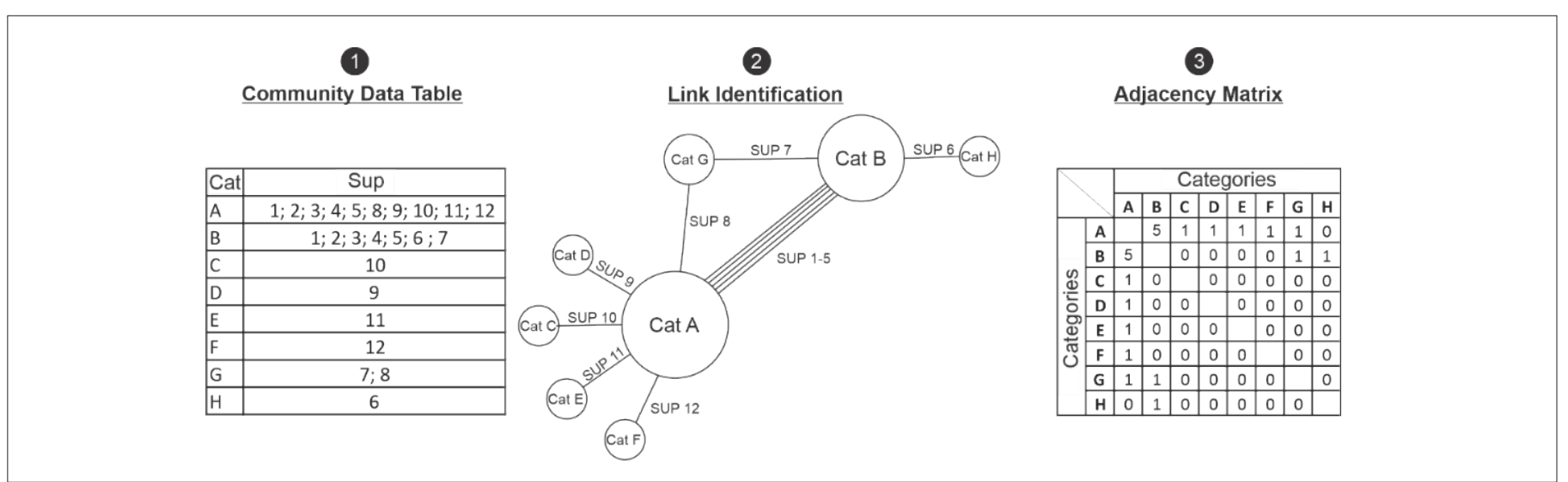

To identify the predominant industries in each community, based on the definitions compiled by Borgatti, Everett, \& Johnson (2013), the metrics shown in Table 2 were used. The network metrics and the graphs generated for each community were useful to identify the structure of the networks that characterize each industry. The nodal metrics were useful to define the actual industry of each identified community. 
Table 2. Network level and nodal level metrics used for analysis

\begin{tabular}{|c|c|c|}
\hline Type & Metric & Description \\
\hline \multirow{4}{*}{ At the network level } & Community size & It is determined by the number of items of industries that compose a community. \\
\hline & Community density & $\begin{array}{l}\text { It is determined by the ratio obtained from dividing the number of links between industry items and } \\
\text { the total possible linkages if all items were connected. }\end{array}$ \\
\hline & Community Diameter & $\begin{array}{l}\text { It is determined by the sum of the links that are generated between the items of industries that are more } \\
\text { distant in the community. }\end{array}$ \\
\hline & Community centralization & $\begin{array}{l}\text { It is determined by the sum of the difference between the centrality of each industry and the centrality } \\
\text { of the most central industry, divided by the differences between the centrality of each node and the } \\
\text { maximum possible centrality if the most central industry were linked to all industries. }\end{array}$ \\
\hline \multirow{3}{*}{ At the Nodal level } & Weighted grade centrality & $\begin{array}{l}\text { The industry with the highest degree of weighted centrality will mean that there are stronger links } \\
\text { with specific nodes in the network, therefore it will be the one that defines the main orientation of the } \\
\text { community. }\end{array}$ \\
\hline & Ego Size & $\begin{array}{l}\text { It is determined by the number of activities registered in CrunchBase that are linked for each of the } \\
\text { nodes that have the highest degree of weighted centrality in a community. }\end{array}$ \\
\hline & Number of Cliques & $\begin{array}{l}\text { The activity recorded with the greatest number of clients shares links with other activities more fre- } \\
\text { quently than the rest of the industries. }\end{array}$ \\
\hline
\end{tabular}

Note: Descriptions based on definitions of Borgatti, S., Everett, M., \& Johnson, J. (2013) in Analyzing Social Networks.

\section{Findings}

To identify the predominant industries in each community, based on the definitions compiled by Borgatti, Everett, \& Johnson (2013), the metrics shown in Table 2 were used. The network metrics and the graphs generated for each community were useful to identify the structure of the networks that characterize each industry. The nodal metrics were useful to define the actual industry of each identified community.

Table 3. Startup Community Industry Network Metrics

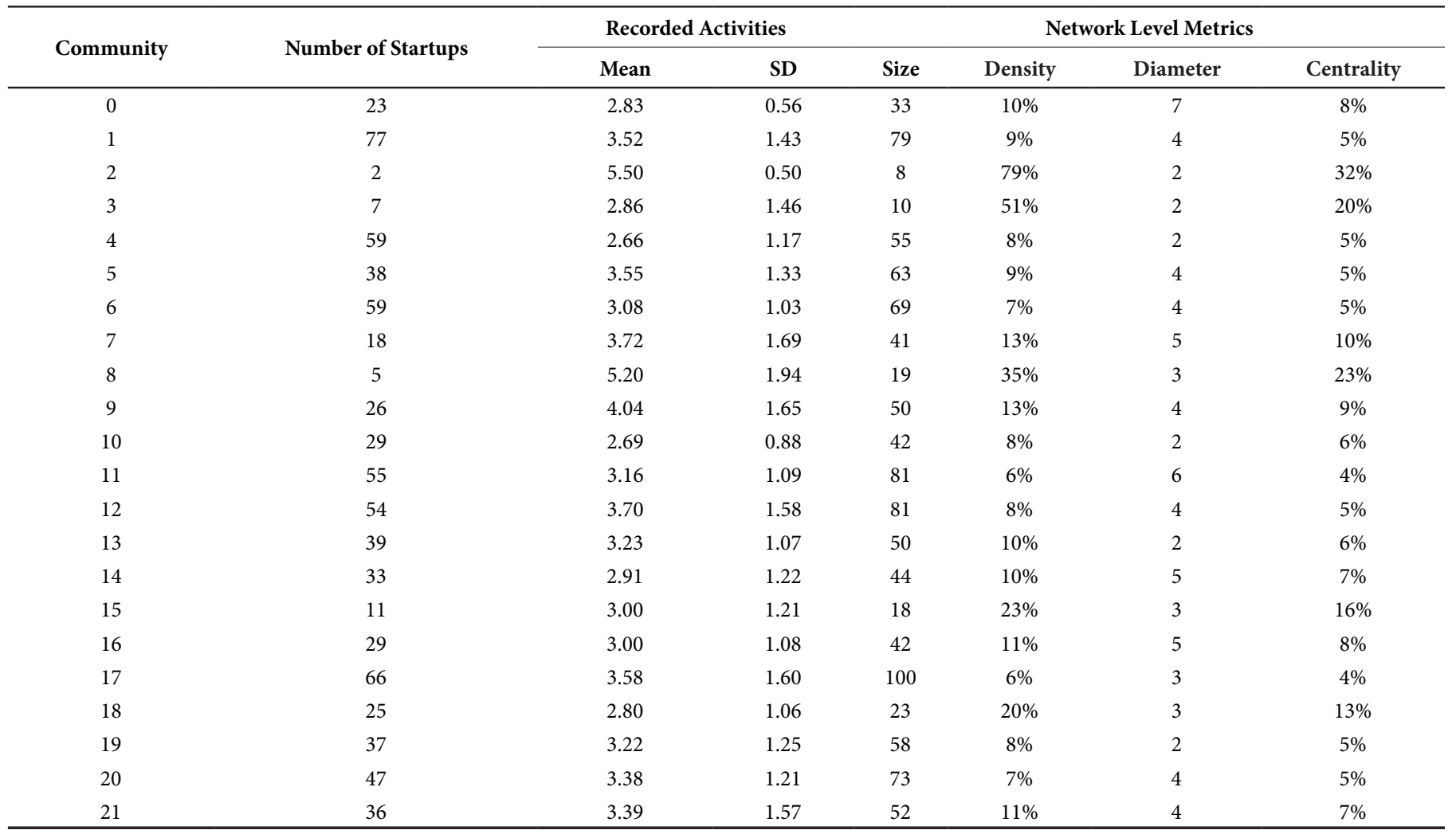

Note: (1) Each community was obtained with modularity function of Gephi 0.9.2. (2) Network level metrics were obtained using UCINET 6.681 
With the exception of small communities (2, 3, 8, 15 and 18), the degrees of centralization are low, which means that there is no industry heading that is absolutely relevant to characterize the community (Borgatti et al., 2013). On the other hand, even with a low value for the degree of centralization, in some communities of larger size and reduced diameter, it is possible that some activities registered in CrunchBase are specifically highlighted $(4,10,13,17$ and 19), especially if the density is low. For example, in the cases of communities with diameters of 2 or 3 nodes, it will imply that most of the nodes are not connected to each other, therefore, there are some nodes to which most of the links are directed. Thus, the low value of centrality is since there is more than one center in the community. This also applies to communities of larger size and diameter $(0,1,5,6,7,9,11,12,14$, 16, 20 and 21). But, as they have a larger diameter, not necessarily all linkages will point to a specific node.

In view of this, identifying the items that are dominant in each community required that some metrics be used at the nodal level, specifically, weighted grade centrality and the number of cliques in which each item participates. In addition, it is necessary to identify what value makes that metric dominant for a specific item. For this purpose, graphs of variation in the degree of centrality and variation in the number of clients per community were drawn up and can be seen in Appendix B. These show that around 3 registered activities accumulate more than $90 \%$ of both indicators. In addition, a large jump is generated with a second large group of activities that do not accumulate more than $20 \%$. In this way, the former are the dominant activities of the community.

Some communities were identified as having the same dominant recorded activities. To decide how to unite these communities, a correlation matrix was drawn up between the networks generated by each community, which can be seen in table 4 . From this matrix, community 21 is highly correlated with community 4 and moderately correlated with communities $2,8,10$ and 15 . The opposite is true of community 3 , which has low correlation coefficients in general. However, the registered activities predominant in this community are repeated in community 4 . All these communities were integrated, being the predominant activities the "e-commerce" and "internet".

Table 4. Correlations between communities with common dominant activities

\begin{tabular}{|c|c|c|c|c|c|c|c|}
\hline Community & 2 & 3 & 4 & 8 & 10 & 15 & 21 \\
\hline 2 & 1.0 & 0.2 & 0.3 & 0.3 & 0.4 & 0.1 & 0.3 \\
\hline 3 & & 1.0 & 0.2 & 0.2 & 0.3 & 0.1 & 0.3 \\
\hline 4 & & & 1.0 & 0.3 & 0.2 & 0.3 & 0.8 \\
\hline 10 & & & & & 1.0 & 0.2 & 0.4 \\
\hline 15 & & & & & & 1.0 & 0.3 \\
\hline 21 & & & & & & & 1.0 \\
\hline
\end{tabular}

Note: Pearson's correlation coefficients between one-mode adjacency matrices were calculated using UCINET 6.681

Thus, it is determined that there are 16 predominant industries. As can be seen graphically in Appendix A, these industries are linked by their nodes, which confirms the argument that the boundaries of startup industries are diffuse. Now, it is necessary to identify what is the degree of relationship between the industries formed. To this end, similarity mea- sures were calculated at the structural level between the nodes of each industry (Borgatti et al., 2013). In other words, the industries formed may be similar because of the linkage in the activities that characterize them. It is then possible to compare them by this similarity through the correlation of the adjacency matrices as can be seen in Table 5.

Table 5. Correlation between the startup industries

\begin{tabular}{|c|c|c|c|c|c|c|c|c|c|c|c|c|c|c|c|c|}
\hline Industry & 1 & 2 & 3 & 4 & 5 & 6 & 7 & 8 & 9 & 10 & 11 & 12 & 13 & 14 & 15 & 16 \\
\hline 1. E-comerce & 1.0 & 0.2 & $0.9^{*}$ & 0.0 & $-0.8^{*}$ & 0.1 & 0.2 & 0.3 & 0.0 & 0.0 & - & $0.37 \sim$ & $0.5 \sim$ & -0.0 & 0.0 & 0.2 \\
\hline 2. FinTech & & 1.0 & $0.5 \sim$ & -0.5 & 0.2 & 0.2 & $0.4 \sim$ & -0.4 & $0.7 \sim$ & 0.3 & $0.8^{*}$ & -0.2 & $0.3 \sim$ & -0.1 & -0.2 & 0.3 \\
\hline 3. Software & & & 1.0 & $0.4 \sim$ & $-0.4 \sim$ & -0.5 & -0.1 & 0.1 & $-0.3 \sim$ & 0.2 & $-0.4 \sim$ & $-0.8^{*}$ & 0.2 & 0.1 & 0.1 & 0.1 \\
\hline 4. HealthTech & & & & 1.0 & $-0.3 \sim$ & 0.2 & -0.2 & 0.3 & -0.1 & 0.1 & 0.1 & -0.1 & 0.1 & 0.1 & 0.2 & 0.2 \\
\hline 5. CleanTech & & & & & 1.0 & 0.2 & 0.3 & 0.1 & -0.2 & 0.0 & 0.1 & -0.2 & -0.1 & 0.1 & - & 0.3 \\
\hline 6. AdTech & & & & & & 1.0 & -0.1 & 0.3 & -0.0 & -0.1 & 0.2 & 0.1 & -0.3 & 0.0 & -0.1 & 0.1 \\
\hline 7. Apps & & & & & & & 1.0 & 0.0 & -0.2 & -0.2 & -0.0 & -0.0 & $0.4 \sim$ & 0.1 & 0.2 & 0.2 \\
\hline 8. EdTech & & & & & & & & 1.0 & -0.2 & 0.0 & 0.1 & 0.2 & 0.1 & 0.1 & 0.1 & 0.1 \\
\hline 9. InfoTech & & & & & & & & & 1.0 & -0.0 & 0.2 & 0.3 & 0.2 & -0.1 & 0.0 & 0.2 \\
\hline 10. Mobile & & & & & & & & & & 1.0 & 0.1 & 0.2 & 0.2 & 0.2 & $0.3 \sim$ & 0.3 \\
\hline 11. Logistics & & & & & & & & & & & 1.0 & 0.3 & -0.0 & 0.1 & 0.2 & -0.1 \\
\hline 12. SaaS & & & & & & & & & & & & 1.0 & 0.1 & 0.0 & 0.2 & 0.2 \\
\hline 13. Analytics & & & & & & & & & & & & & 1.0 & 0.1 & 0.0 & 0.1 \\
\hline 14. TravelTech & & & & & & & & & & & & & & 1.0 & 0.3 & 0.3 \\
\hline 15. Gamming & & & & & & & & & & & & & & & 1.0 & 0.0 \\
\hline 16. AI & & & & & & & & & & & & & & & & 1.0 \\
\hline
\end{tabular}

Note: Pearson's correlation coefficients between similarity matrices between industry network nodes of the startups using UCINET 6.681. Numbers accompanied by "*” correspond to strong correlations and “ " corresponds to moderate correlations.

Without considering the strength of the relationship, it can be seen that "Artificial Intelligence" is the industry that has the greatest number of positive di-

ISSN: 0718-2724. (http://jotmi.org)

Journal of Technology Management \& Innovation (c) Universidad Alberto Hurtado, Facultad de Economía y Negocios. 
rect relationships (14), followed by E-commerce, EdTech and Gamming (13). On the other hand, the industries with less positive direct relationships are InfoTech (7) and Apps (8). Further evidence that the boundaries between startup industries are diffuse is that less related industries are positively correlated with more than $50 \%$ of the total industries.

The intensity of the positive correlations allows us to identify which industries are most related. These relationships suggest the integration of some processes in the startups that, due to their innovation capabilities and the flexibility of these ventures, extend their fields of action to internally provide services that could be offered by startups from other industries. It could also explain the intention of innovative ventures to provide a broader value proposition, generating services attributable to more than one industry, to satisfy various requirements of the target customers.

On the other hand, inverse correlations are identified between the structural similarities of the nodes. This means that the links between the activities that characterize the startups that make up these industries are dissimilar from each other. These industries would have better defined boundaries since they do not need to interact with activities from other industries to generate their value propositions.

\section{Discussion}

Sixteen startup industries have been identified (see network networks in Appendix C). These present a pattern in their structure: (i) a dominant category, which has a higher degree of centrality, a larger ego size and participates in most 3-node cliques that are formed in the network. (ii) The categories of the technologies used to generate products in this startup industry. (iii) The categories of uses, which correspond to the applications that the products generated in this industry could have. The last two have lower values of ego size and cliques with respect to the predominant category. However, some stand out because they are more frequently linked to the dominant category. In addition, the analysis also showed that some industries are related to each other, either as suppliers or customers (see Appendix D).

Therefore, in the startup industries, the aim is no longer to serve a homogeneous group of clients as Porter (1998), claims, when he defines how an industry is formed. To be more precise, it is an expression of the complexity of the creation of startups, which make use of the scarce resources that they can access to solve the problems of a market segment through innovative products through the process of experimentation. Thus, the entrepreneurial bricolage explained by Baker \& Nelson (2005) and the effectuation theory proposed by Sarasvathy (2001) are transferred to vertical industries (Xtech) crossed with fuzzy limits, as has been demonstrated with the analysis of communities in startup networks carried out in this research.

In addition, the low value of the modularity coefficient obtained for the formation of communities, given that the criteria of linkage are the activities in which these startups participate, would be an indication that what is affirmed by Libert et al.(2016), is being fulfilled, when it refers to the fact that the limits of the industries are disappearing.
The analysis also identified four types of industries. First, the mature industries that serve other industries. This is the case for the software, mobile and apps industries. Here it is important to note that the industry and the predominant item are nominally the same and have a high degree of centrality. With egos that are connected to more than $90 \%$ of the items and participate in more than $95 \%$ of the cliques. In mature entrepreneurial ecosystems, if the life cycle is considered, these industries are in decline (Startup Genome, 2018). In this industry, the predominant technology for its operation is the Internet, so according to Steve Case (2016), the companies that make up these industries would correspond to the second wave of the development of startups.

Secondly, growth industries serving other industries are identified. These are smaller (compared to the former) considering the number of startups. In this category we find the SaaS industry (59\% of the size and $70 \%$ of the cliques), Artificial Intelligence ( $85 \%$ of the size and $85 \%$ of the cliques) and Analytics (78\% of the size and $79 \%$ of the cliques). In relative terms they are less predominant in their networks, with respect to mature industries, which implies that they are not completely linked to all the items that appear in the network. Therefore, they are not widely used in their own industry. However, they are based on technologies that correspond to the third wave (Case, 2016) like machine learning, big data and the internet of things. These are the industries that in mature entrepreneurial ecosystems are considered to be growing (Startup Genome, 2019). It could be said that these first two categories of industries are cross-cutting, as they serve several industries.

The third category relates to industries that facilitate online sales. Here we identify E-commerce, which is the largest industry in terms of number of participants. It has the Internet as its predominant technology and is mainly used in the fashion and retail industries. In mature ecosystems it is classified as a declining industry (Startup Genome, 2019). Following Case (2016), it is again a second wave industry. Correlations between the similarities of the network nodes show that E-commerce is related to the Software, SaaS, and Analytics industries. All these industries generate information flow services that make E-commerce possible, which supports Fujimoto's (2018) argument that industries are linked by competitive or complementary transaction networks.

This category also includes the AdTech industry, which focuses on advertising using social media platforms and digital media for the implementation of marketing campaigns. Although AdTech is weakly correlated with E-commerce, it shares some nodes and cliques. This suggests that AdTech is not only focused on promoting sales of digital services. Also, the fact that it has low correlation rates with all other industries suggests that it may have less diffuse industry boundaries. Facilitating online sales also requires the Logistics and Transportation industry. In this area it is worth noting that a second center appears on the net, which is the Food and Beverage industry.

Finally, the fourth category is specialized industries. In the sense that the correlations with other specialized industries are weak or indirect. That is, they have better-defined industry boundaries between them. 
Although they maintain links with the Software industry, InfoTech, SaaS, or Artificial Intelligence, since they use the resources of these industries to generate their value offers. As Schwab (2016) claims, these are the industries that have achieved in their value offerings a mix of the physical and the digital domains.

The first specialized industry is FinTech, due to the number of startups, is the most predominant specialized industry in the Pacific Alliance. The network has 2 centers, the financial services and the FinTech itself. Logically, finance is the focus of its use. However, other less traditional uses, such as crowdfunding, as well as services associated with finance, such as accounting, can be appreciated. The second industry in this group is CleanTech, in the case of the Pacific Alliance, is focused on energy use, with the predominant technologies being those related to renewable, solar, and clean energy. Here, the application is mainly in activities of a productive nature.

The third specialized industry is HealthTech, here the predominant item is health care, highlighting biotechnology as the most frequent technology and the uses are mainly concentrated in the areas of medical services, personal care and maintenance of physical condition and welfare. The fourth industry is the EdTech, here it is noteworthy that its uses have been concentrated in adult education and the formation of learning communities. The fifth industry in this group is TravelTech, whose predominant use is in travel, with both recreational and business travel being prominent. Finally, the smallest specialized industry is Gamming, which has strong links with the mobile industry, specifically with mobile applications.

The categories of industries proposed from the findings of the analysis of the structure of the startup industries of the Pacific Alliance only confirm that the traditional systems of industrial classification based on the theory of industrial organization are no longer applicable in the world of innovative entrepreneurship. As Parker et al. (2016) argue, the combined use of capabilities developed in different industries means that these classification mechanisms are not useful when the startups themselves generate changes that can redefine an industry in relatively short periods of time.

\section{Conclusion, Limitation and Future Research}

\section{Theorical Implications.}

Based on the classifications of economic activities carried out by a specialized entity dedicated to generating information for decision making by investors in startups, using social network analysis on a sample of this type of enterprise operating in the Pacific Alliance, it has been proven, as Libert et al. (2016) claim, that the classifications of industries traditionally used such as the ISIC are not representative for innovative ventures.

Furthermore, taking the theory of effectuation (Sarasvathy, 2001) and entrepreneurial bricolage (Baker \& Nelson, 2005), the results suggest that the behavior of startups to take all the resources that are available and constantly experiment using different technologies, make the uses and applications of these cross the boundaries of industries, becoming difficult to be distinguished. Thus, the main contribution of this research is to propose a classification of the startup industries that takes this feature. This follows a pattern of industry (dominant activity), applied technology and specific use. It seems to be a less complex classification than the ISIC morphology, which is based on the characteristics of the products generated, the uses to which they are put and the inputs, processes and production technology used (T. Y. Kim et al., 2014).

\section{Managerial and Policy Implications.}

This study raises two managerial implications for the founders of the startups in the Pacific Alliance. In principle, the industries that are oriented to the commercialization of products online could have problems of growth in the short term, since it is an industry that hosts the largest number of startups, whose technological applications are widely known, so there are no barriers to entry and competition is high. Thus, it is possible that startups entering this industry, without a powerful business model, lose their uniqueness by becoming a traditional company. Better opportunities can be found in transversal service industries, such as artificial intelligence, analytics, and SaaS. These not only represent an opportunity because the industries are just beginning to be promoted, but also because of their potential to provide services to specialized industries.

Secondly, founders of startups can find better conditions to undertake in the specialized industry of fintech. There is a greater number of startups in this area that have developed the conditions for this type of enterprise to find human capital and entrepreneurial capital to support the creation and growth of the business, in addition to a market that expects solutions to incorporate digital solutions to their processes of asset management, billing, payment and financing.

On the other hand, there are also implications for public policy makers. Industries such as Advanced Manufacturing, Robotics, Blockchain, AgTech, New Foods, and Cyber Security do not appear as products of the analysis. These are the growth industries in developed entrepreneurial ecosystems (Startup Genome, 2019). It appears that the Pacific Alliance startups that make up the sample studied are focusing on industries that have become traditional, such as software, or are in the decline stage of their life cycle. Although the ecosystems in the countries of the alliance are not very developed (Kantis, Federico, \& Ibarra, 2017), public policies are needed to direct innovative ventures towards third wave industries the fourth industrial revolution.

Specifically, public policy makers should focus on industries related to agriculture and biotechnology. Such startups are rare, and applied NSA algorithms have associated these items with dominant industries. In the case of agriculture, it has been associated with Clean Tech, and in the case of biotechnology it has been associated with Health Tech. Both industries should take up important positions in countries with intensive agricultural activity or high levels of biodiversity, such as those that make up the Pacific Alliance (PwC, 2016). 


\section{Limitations and Future Research.}

This research is not free of limitations. First, there are few high-tech startups, which means that the classification algorithms applied cannot distinguish them, so they are hidden in industries that have higher levels of centrality. Second, the tables have been constructed from public information on Crunch Base startups, which is not audited by any official entity, so they could be subject to the confirmation biases of the reporters themselves, who could assume that they operate in an industry with which they have little relationship. Third, the data used from Crunch Base does not distinguish between startups and some traditional companies; data cleaning was manual, so there may be some involuntary omissions. Finally, the data analyzed was obtained in May 2019, and the effects of the pandemic (COVID 19) have changed some structures such as the push for startups from EdTech, HealthTech, and FinTech.

The results of this research also suggest some guidelines for future research. Different types of industries have been identified, however it is stated that startups in mature industries have greater difficulties in attracting financing (Startup Genome, 2018). It would be interesting to determine how in the ecosystems of the Pacific Alliance, entrepreneurial capital is related to startups classified by type of industry. Furthermore, can mature industries still be classified as startups? It is important to determine how growth rates differ between different types of industries; it could be that startups in mature industries do not have accelerated growth, so they lose the status of startups (Picken, 2017). Finally, the industry classification methodology could be applied to networks of startups in more developed ecosystems. It would be interesting to determine how the industries of the startups differ between emerging and mature ecosystems.

\section{References}

Acs, Z. (2010). High-Impact Entrepreneurship. In Z. Acs \& D. Audretsch (Eds.), Handbook of Entrepreneurship Research. An Interdisciplinary Survey and Introduction (2nd ed., pp. 165-182). New York, USA: Springer.

Alianza del Pacífico. (2016). 4 Naciones. Un acuerdo de integración profunda. Lima: Alianza del Pacífico. Retrieved from https://alianzapacifico.net/download/cartilla-alianza-del-pacifico-2017/

Álvarez, M., Pavan, J., Raurich, A., Pertuzé, J., Franco, M., Moreno, J., ... Zúñiga, M. (2018). Brechas para el Emprendimiento en la Alianza del Pacífico. Santiago de Chile: Observatorio Estratégico de la Alianza del Pacífico. Retrieved from http://brechas.asela.org/static/media/estudio_brecha_oeap.9c5c3040.pdf

Alvarez Salazar, J. (2020). Organizational resources and survival of startups firms - a qualitative analysis in the Peruvian context. Academia Revista Latinoamericana de Administracion, ahead-ofprint(ahead-of-print). https://doi.org/10.1108/ARLA-04-2020-0080

Aulet, B. (2013). Disciplined Entrepreneurship. 24 steps to a successful startup. New Jersey: John Wiley \& Sons, Inc.
Bain, J. (1959). Industrial Organization. California: Wiley \& Sons.

Baker, T., \& Nelson, R. (2005). Creating Something from Nothing: Resource Construction through Entrepreneurial Bricolage. Administrative Science Quarterly, 50(3), 329-366.

Bessen, J. E., Impink, S., Seamans, R., \& Reichensperger, L. (2018). The Business of AI Startups. SSRN Electronic Journal, 28(18), 34. https://doi.org/10.2139/ssrn.3293275

Bettis, R. A. (1998). Commentary on "redefining industry structure for the information age" by J. L. Sampler. Strategic Management Journal, 19(4), 357-361. https://doi.org/10.1002/(SICI)10970266(199804)19:4<357::AID-SMJ987>3.0.CO;2-X

Blondel, V. D., Guillaume, J., \& Lefebvre, E. (2008). Fast unfolding of communities in large networks. Journal of Statistical Mechanics: Theory and Experiment, 10, 1-12. https://doi.org/10.1088/1742$5468 / 2008 / 10 / \mathrm{P} 10008$

Borgatti, S., Everett, M., \& Johnson, J. (2013). Analyzing Social Networks (p. 320). p. 320. London: SAGE Publications, Inc.

Carrington, P., \& Scott, J. (2011). Introduction. In The SAGE Handbook of Social Network Analysis (pp. 1-8). Cornwall: SAGE Publications, Inc.

Case, S. (2016). The Third Wave: An Entrepreneur's Vision of the Future. New York: Simon \& Schuster.

Clark, L. (2014). Waze cofounder: "fall in love with the problem , not the solution." Retrieved December 2, 2019, from Wired website: https://www.wired.co.uk/article/waze-uri-levine

Coviello, N. E., \& Joseph, R. M. (2012). Creating major innovations with customers: Insights from small and young technology firms. Journal of Marketing, 76(6), 87-104. https://doi.org/10.1509/jm.10.0418

Crunchbase. (2019). What categories are included in Crunchbase? Retrieved June 14, 2019, from Crunchbase Knowledge Center website: https://support.crunchbase.com/hc/en-us/articles/360009616373

De Nooy, W., Mrvar, A., \& Batagelj, V. (2018). Exploratory Social Network Analysis with Pajek (3rd ed.). Cambridge: Cambridge University Press. https://doi.org/10.1017/9781108565691

Fortunato, S. (2010). Community detection in graphs. Physics Reports, 486(3-5), 75-174. https://doi.org/10.1016/j.physrep.2009.11.002

Fujimoto, T. (2018). A Desing-Information-Flow View of Industries, Firms, and Sites. In Industrial Competitiveness and Design Evolution (pp. 5-41). Tokyo: Springer Japan KK. https://doi.org/10.1007/9784-431-55145-4

Hanneman, R. A., \& Riddle, M. (2011a). A brief Introduction to Analyzing Social Network Data. In J. Scott \& P. Carrington (Eds.), The SAGE Handbook of Social Network Analysis (pp. 331-339). Cornwall: SAGE Publications, Inc. 
Hanneman, R. A., \& Riddle, M. (2011b). Concepts and Measures for Basic Network Analysis. In P. Carrington \& J. Scott (Eds.), The SAGE Handbook of Social Network Analysis (pp. 340-369). Cornwall: SAGE Publications, Inc.

Hanneman, R., \& Riddle, M. (2005). Introduction to social network methods. California: University of California.

Hechavarría, D. M., Matthews, C. H., \& Reynolds, P. D. (2016). Does startup financing influence startup speed? Evidence from the panel study of entrepreneurial dynamics. Small Business Economics, 46(1), 137-167. https://doi.org/10.1007/s11187-015-9680-y

Hougaard, S., \& Duus, H. J. (2017). Competing in the Digital Age. Journal of General Management, 24(3), 1-10. https:/doi. org/10.1177/030630709902400301

Ingham, A., \& Kodner, L. (2017). PrivCo versus Crunchbase. Journal of Business and Finance Librarianship, 22(3-4), 250-252. https://doi. org/10.1080/08963568.2017.1372019

Isenberg, D., \& Dillon, K. (2013). Worthless, Impossible and Stupid. How Contrarian Entrepreneurs Create and Capture Extraordinary Value. Boston: Harvard Business Review Press.

Kantis, H., Federico, J., \& Ibarra, S. (2017). Condiciones Sistémicas para el Emprendimiento Dinámico. América Latina: Avances y retrocesos en perspectiva. Buenos Aires: Prodem.

Kantis, H., Federico, J., \& Ibarra, S. (2019). Index of Dynamic Entrepreneurship. Entrepreneurship as a Vehicle to Enhance Digitalization. Buenos Aires. Retrieved from https://prodem.ungs.edu.ar/publicaciones_prodem/index-of-dynamic-entrepreneurship-ide-entrepreneurship-as-a-vehicle-to-enhance-digitalization/

Kantis, H., Federico, J., \& Magendzo, A. (2016). Condiciones sistémicas e institucionalidad para el emprendimiento y la innovación. Hacia una agenda de integración de los ecosistemas de los países de la Alianza del Pacífico.

Kim, T. Y., Koo, Y., Ook, D., \& Kim, Y. (2014). The Necessity of a New Industrial Classification Based on Value-Creation Behavior. In T. Kim \& A. Heshmati (Eds.), Economic Growth: The New Perspectives for Theory and Policy (pp. 1-323). Heidelberg, Germany: Springer.

Kodama, M. (2017). Comparative case studies and new implications. In M. Kodama (Ed.), Ma Theory and the Creative Management of Innovation (pp. 229-263). New York, USA: Palgrave Macmillan.

Kuivalainen, O., Saarenketo, S., \& Puumalainen, K. (2012). Startup patterns of internationalization: A framework and its application in the context of knowledge-intensive SMEs. European Management Journal, 30(4), 372-385. https://doi.org/10.1016/j.emj.2012.01.001

Lambiotte, R., Delvenne, J. C., \& Barahona, M. (2014). Random walks, Markov processes and the multiscale modular organization of complex networks. IEEE Transactions on Network Science and Engineering, 1(2), 76-90. https://doi.org/10.1109/TNSE.2015.2391998
Libert, B., Beck, M., \& Wind, Y. (2016). Why Are We Still Classifying Companies by Industry? (p. 4). p. 4. Boston: Harvard Business Review. Retrieved from https://hbr.org/2016/08/why-are-we-still-classifyingcompanies-by-industry

Lougen, C. (2017). CB Insights. Journal of Business and Finance Librarianship, 22(3-4), 247-250. https://doi.org/10.1080/08963568.201 7.1372018

Marin, A., \& Wellman, B. (2011). Social Network Analysis : An Introduction. In J. Scott \& P. Carrington (Eds.), The SAGE Handbook of Social Network Analysis (pp. 11-25). Cornwall: SAGE Publications, Inc.

Missaoui, R., \& Sarr, I. (2014). Social Network Detection and Community Analysis and Evolution. In Lecture Notes in Social Networks. Switzerland: Springer.

Mohr, J., Sengupta, S., \& Slater, S. (2010). Marketing of Hig-Technology Productos and Innovations (3rd ed.). New Jersey: Pearson Prentice Hall.

Munir, K. A., \& Phillips, N. (2002). The concept of industry and the case of radical technological change. Journal of High Technology Management Research, 13(2), 279-297. https://doi.org/10.1016/S10478310(02)00046-9

OCDE. (2016). Startup América Latina 2016. Construyendo un Futuro Innovador. Paris: OECD Publishing.

Parker, G., Van Alstyne, M., \& Choudary, S. P. (2016). Platform Revolution: How Networked Markets Are Transforming the Economy And How to Make Them Work for You. New York: W.W. Norton \& Company.

Pavlou, P. A., \& El Sawy, O. A. (2011). Understanding the Elusive Black Box of Dynamic Capabilities. Decision Sciences, 42(1), 239-273. https://doi.org/10.1111/j.1540-5915.2010.00287.x

Phillips, R. L., \& Ormsby, R. (2016). Industry classification schemes: An analysis and review. Journal of Business and Finance Librarianship, 21(1), 1-25. https://doi.org/10.1080/08963568.2015.1110229

Picken, J. C. (2017). From startup to scalable enterprise: Laying the foundation. Business Horizons, 60(5), 587-595. https://doi. org/10.1016/j.bushor.2017.05.002

Pitchbook. (2019). What are industry verticals? Retrieved June 14, 2018, from PitchBook Blog website: https://pitchbook.com/blog/ what-are-industry-verticals\#wearables

Porter, M. (1998). Competitive Strategy. Techniques for Analyzing Industries and Competitors. New York: The Free Press.

Porter, M. (2008). The Five Competitive Force That Shape Strategy. In On Competition (pp. 3-35). Boston: Harvard Business Review Book.

Porter, M. (2009). Estrategia Competitiva. Técnicas para el Análisis de la Empresa y sus Competidores. Madrid: Pirámide. 
PwC. (2016). El futuro de la Alianza del Pacífico. Integración para un crecimiento productivo. Mexico D.F. Retrieved from https://www.pwc. pe/es/publicaciones/assets/futuro-alianza-pacifico.pdf

Rajahonka, M. (2019). Meso-analysis: Modes of Cross-innovation Between Education and Audiovisual Sector. In Emergence of Cross - Innovation Systems. Audiovisual Industries Co - innovating with Education, Health Care and Tourism (Ibrus, Ind, pp. 71-94). Bingley: Emerald Publishing.

Sampler, J. (1998). Redefining industry structure for the information age. Strategic Management Journal, 19(4), 343.

Sarasvathy, S. D. (2001). Causation and effectuation: Toward a theoretical shift from economic inevitability to entrepreneurial contingency. Academy of Management Review, 26(2), 243-263. https://doi. org/10.5465/AMR.2001.4378020

Schwab, K. (2016). La cuarta revolución industrial. Bogota: Debate. Sharma, S. (2017). PitchBook. Journal of Business and Finance Librarianship, 22(3-4), 244-247. https://doi.org/10.1080/08963568.2017.1372017

Startup Genome. (2018). Global Startup Ecosystem Report 2018. San Francisco. Retrieved from https://startupgenome.com/report2018/

Startup Genome. (2019). Global Startup Ecosystem Report 2019. San Francisco. Retrieved from https://startupgenome.com/reports
Tatsumoto, H. (2018). Evolution of Business Ecosystems. In Industrial Competitiveness and Design Evolution (pp. 155-187). Tokyo: Springer Japan KK.

Teddlie, C., \& Tashakkori, A. (2009). Fundations of Mixed Methods Research. Integrating Quantitative and Qualitative Approaches in the Social and Behavioral Sciences. California: SAGE Publications, Inc.

Teece, D. J. (2007). Explicating Dynamic Capabilities: The Nature and Microfoundations of (Sustainable) Enterprise Performance. Strategic Management Journal, 28(13), 1319-1350. https://doi.org/10.1002/ smj.64()Received

United Nations. (2008). International Standard Industrial Classification of All Economic Activities (ISIC), Rev.4. New York.

Wright, F. (2017). How do entrepreneurs obtain financing? An evaluation of available options and how they fit into the current entrepreneurial ecosystem. Journal of Business and Finance Librarianship, 22(3-4), 190-200. https://doi.org/10.1080/08963568.2017.1372011

Yao, Y., Si, X., \& Ye, W. (2016). Definition and Statistical Classification of Language Service Industry. International Conference on Industrial Economics System and Industrial Security Engineering (IEIS). Sydney: IEEE. https://doi.org/10.1109/ieis.2016.7551854

Yousefi Nooraie, R., Sale, J. E. M., Marin, A., \& Ross, L. E. (2020). Social Network Analysis: An Example of Fusion Between Quantitative and Qualitative Methods. Journal of Mixed Methods Research, 14(1), 110-124. https://doi.org/10.1177/1558689818804060 
